\title{
After the Launch of the CSHP Strategic Plan, What's Next?
}

\author{
Lauza Saulnier
}

$\mathrm{T}$

he Canadian Society of Hospital Pharmacists (CSHP)

introduced its new strategic plan at the final Summer Educational Sessions, held in Ottawa in August 2015. The Strategic Plan 2015-2018, available at www.cshp.ca/aboutUs/ strategicPlan_e.asp, highlights CSHP's vision, goals, and priorities for improvement.

The plan lays out the future direction of the organization, under 4 key strategic areas: pharmacists' practice, member and volunteer engagement, governance, and organizational effectiveness. Sixteen strategic goals aligned with these strategic areas have been identified to answer the following questions:

- What improvements is CSHP committing to in terms of member benefits?

- How will CSHP financially sustain the programs and services it offers?

- What internal processes should CSHP improve if it is to meet members' expectations and the organization's financial obligations?

- How will CSHP ensure that its staff and volunteers, its technology, and its culture are ready to deliver on its strategic goals?

Converting an organization's vision and strategic priorities into actions that will achieve a desired outcome can often be more difficult than envisioned. Robert Kaplan and David Norton, originators of the balanced scorecard concept, have described a comprehensive management system that can be used to effectively execute a strategic plan (Execution Premium: Linking Strategy to Operations for Competitive Advantage, Harvard Business Press, 2008). Strong practice examples can also be derived from the work of other national organizations. The Canadian Pharmacists Association led the Blueprint for Pharmacy, a multistakeholder collaborative initiative to develop and achieve a vision for the future of pharmacy in Canada (see http://blueprintforpharmacy.ca/). The Canadian Patient Safety Institute adopted "Patient Safety
Forward with Four" as its 2013-2018 Business Plan, aiming to align patient safety in Canada (see www.patientsafetyinstitute. ca/en/About/PatientSafey ForwardWith4/Pages/ default.aspx).

If an organization is to be successful, it is imperative that all levels of the organization align with and

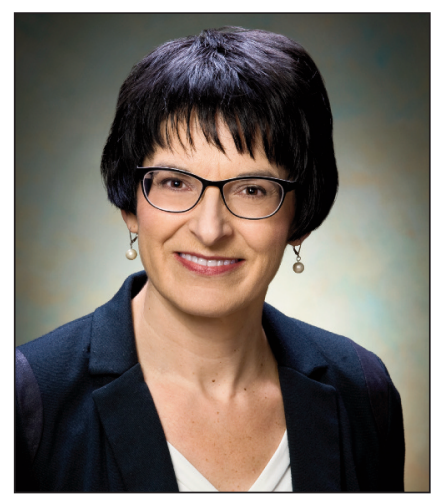
understand the collective vision and strategic direction. Leaders across CSHP will therefore be involved in "cascading" the strategic plan to the provincial Branches, affiliated boards, and committees, such that their objectives and actions will be integrated within the corporate strategic priorities.

As is the case for many organizations, CSHP's greatest asset is its membership. The inclusion and engagement in this process of everyone within the Society will lead to effective execution of the strategic plan, by building on members' strengths and thus contributing to optimal local operations, achievement of organizational goals, and overall strategic success.

As strategic management practices are adopted across the association, I look forward to partnering with each member, volunteer, and employee to enhance and sustain CSHP's longstanding and highly valued services, to develop new strategic initiatives, and to realize our shared vision.

Lauza Saulnier, BSC(Pharm), ACPR, is President Elect and Vision Liaison for the Canadian Society of Hospital Pharmacists. 